\title{
Hindsight isn't always 20/20
}

\author{
C. Youngson ${ }^{1}$
}

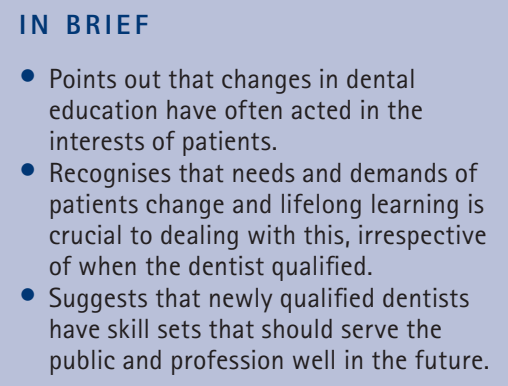

This article provides a personal perspective on how both dentistry and dental education have changed over the past 30 years. The discussion spans transformations in infection control, dental materials, techniques and outreach.

In response to a recent $B D J$ opinion piece by $\mathrm{S}$. Islam ${ }^{1}$ regarding the inexperience of newly qualified dentists I thought that a personal perspective may be useful. As an individual who qualified 30 years ago I could be considered to have come from that 'far-off golden era with lots of experience' that prepared me fully for completely independent practice on qualification. I've been involved in teaching for many of the subsequent years and so have seen the evolution of the profession, the changes in education, and the move from baby-boomer dentists to Generation $\mathrm{X}$ and now $\mathrm{Y}$.

\section{QUANTITY OVER QUALITY?}

Of course things aren't as good as they were. Public sanitation, employment laws, abolition of national service and the ubiquity of fluoride toothpastes have all been thin ends of wedges that have led to the disintegration of the 'perfect' society that Dickens described in his time. People hark back to a better time in the past, but when was this precisely - and better for whom? Retrospect tends to be benevolent and people often forget they too had shortcomings in their youth. Furthermore it is worth remembering that what is measured is often chosen because it is easy to measure rather than being of importance.

Professor of Restorative Dentistry, School of Dentistry, University of Liverpool, Pembroke Place, Liverpool, L3 5PS Correspondence to: Professor Callum Youngson Email: c.c.youngson@liverpool.ac.uk

\section{Refereed Paper}

Accepted 28 March 2012

DOI: 10.1038/sj.bdj.2012.416

${ }^{\circ}$ British Dental Journal 2012; 212: 473-474
I apologise if the following list of items makes people reach for ancient texts to find descriptions of my undergraduate experience but a lot has improved since 1982 (not least dress-sense). As a student I had only three main filling materials: amalgam, gold (for clean mouths only) and chemically-curing composite (acidetch commanded an extra fee). Composite (Concise or Isopast) was regarded as a new material gradually replacing silicate, but that material could still be used in 'dirty mouths'. Aspa IV [glass-ionomer cement (GIC)] was also available, but was less than ideal by any measure of success.

My 1982 Conservation requirements were:

- 360 'plastic' points - one per surface. Amalgam/composite/GIC plus an extra point for pins. About 150 restorations

- 120 gold points - two per surface (full veneer crown counted as six). About 25 restorations

- 12 anterior crowns [porcelain jacket crown (PJC) or metal ceramic crown]

- 10 root canal fillings. ('Messing' silver sectional points could be used if a post was subsequently to be placed). One tooth had to be a molar (so three canals in those days) and could be filled with silver points after reaming until clean dentine.

You will note that neither dietary advice nor any form of preventive treatment features on the above list and importantly 'quality' is also missing. The number was the important thing. In the past, dental schools used to produce graduates who had done a lot, with or without an understanding of what they had performed while working under instruction. Usually there was a separate knowledge of the theory of dentistry. With respect to clinical experience - how many patients really 'needed' a Class IV inlay in the days when they were a requirement of some curricula? Did the need to gain a number of restorations act as a perverse incentive? Did the undergraduate requirements always work in the patients' best interests?

\section{CHANGES IN DENTISTRY}

I haven’t done any Class I gold inlays since I qualified. The one bridge I placed as an undergraduate was fixed-fixed, all-gold, crown retained, with a 'hygienic' pontic on minimally restored abutment teeth, to replace a missing lower first molar. I wouldn't even do it now. I'd advise the patient that it would not improve aesthetics or function and was unnecessarily destructive. Of my 12 crowns, 8 were replacements. I aspirated while the staff did almost all the work for me. I held the impression tray and cemented them. Of the six PJC's I made personally, the marvellous technician Tom Stoddart (re)made them. Perhaps my BDS should be rescinded. Cavities were made large and 'self-cleaning' with nice sharp internal angles (inverted cone burs were de rigueur) and we see the cusps cracking off now showing how good we were then.

Infection control was paid lip service, nobody wore gloves for normal operative care and instruments were often 'sterilised' in boiling water. In fact, in those days before HIV and CJD, the greatest infection concern was to avoid contaminating a root 
canal that had been rendered 'sterile' to the bacterial culture techniques then available.

Since qualification, in the area of conservative dentistry alone, I have had to learn: light curing of composites, resinmodified GIC and compomers, internal and external bleaching, endodontic microscopy, rotary endodontics using NiTi, thermal condensation of gutta-percha, surgical endodontics, use of mineral trioxide aggregate (MTA), dentine bonding (all of it), porcelain laminate veneers and resin bonded crowns, resin bonded bridgework, all-ceramic crowns and bridgework, endosseous implants, minimally invasive dentistry, occlusion (that's right I did all those fillings and crowns as an undergraduate without even knowing how the teeth fit together or slide over each other), the diagnosis of tooth wear (and treatment of this using composite build-ups rather than crowns) - that is effectively everything I do now. Isn't this what lifelong learning is about?

\section{EMPHASISING UNDERSTANDING}

The emphasis must surely be on producing a student who is capable of doing many things with a deep understanding of what is in the patients' best interests and the basic skills to apply this knowledge to (as yet unknown) new materials, techniques and the patients' needs. Of course they need to have skills and experience as an undergraduate to prepare them for practice, and virtually all students now gain primary care 'outreach' experience which my generation never did. The General Dental Council's (GDC's) new Preparing for Practice guidance (GDC 2012) recognises the many required skills and this will be the driver for future undergraduate education. For those who argue that students must do a number of items of treatment - what things should be counted and what absolute number must be reached? Would one less be too few and what action should be taken if there was over-prescription to reach the number? Real measures of success for our profession are much more difficult to record because they often mean the disease has never arisen as a result of successful preventive interventions.

General dental practice and dental foundation training (ie dental foundation training year one [DF1] and vocational training [VT]) have also changed, including the acronyms. The latter didn't even exist when I qualified. The average DF 1 trainee now will complete very few crowns in their first year - many will also see few complete denture patients. The number of crowns prescribed in general dental practice in England has fallen markedly. Is this only because of UDA values or also because there are alternative forms of, minimally invasive, treatment being delivered?

\section{CONCLUSION}

Over 28 years of teaching I can definitely say that our new dental graduates are every bit as capable as my peers but the world has changed, and every generation thinks those behind them have the "wrong' values. Numbers of things done (well or badly?) are a poor measure of what people are capable of. The ability to diagnose and treat holistically, while conserving healthy tissue is a more pertinent skill. I'm happy to defend the new graduates, the schools that produce them, and the regulator who inspects them. We learn a lot of dentistry as an undergraduate (which is why it takes so long) but it's not just fillings, it's all of dentistry to the level required by the GDC which is why they inspect us. After graduation we learn so much more and that takes the whole of our practising careers. In our increasingly complex world we should beware of simplistic solutions. Before we 'point out the speck' in another's eye we should perhaps try to recall, with full clarity, our own undergraduate careers.

1. S Islam. Devoid of Dentistry. Br Dent J 2012; 212: 163-164. 